\title{
An empirical investigation of intellectual capital components on each others and organizational learning capabilities
}

\author{
Hasan Darvish $^{\mathrm{a}}$, Ali Reza Kafashzadeh ${ }^{\mathrm{b}}$, Mohamad Malekmohamadi Faradonbe ${ }^{\mathrm{c}}$, Ali Reza Naderifar ${ }^{\mathrm{d}}$ \\ and Nabi ollah Nejatizadeh ${ }^{\mathrm{e}}$
}

${ }^{a}$ Department of Economy, Management and Accounting, Payame Noor University, Tehran, Iran

${ }^{b}$ Department of Public Administration,Payame Noor University,Tehran, Iran

${ }^{c}$ Department of Public Administration, Azad University of Dehaghan, Esfahan, Iran

${ }^{d}$ Department of Public Administration, Zahedan University, Zahedan, Iran

${ }^{e}$ Department of business management, Payame Noor University, Tehran, Iran

\section{H R O N I C L E}

Article history:

Received October 2, 2012

Received in revised format

28 November 2012

Accepted 20 December 2012

Available online

December 242012

Keywords:

Human capital

Structural capital

Relational capital

Organizational learning

\section{Introduction}

One of the challenges in contemporary area of management and organizational behavior is to generate and strengthen organizational learning. Organizational learning could be gained through human capital or structural and helps people build better relationships and cooperation. Darvish et al. (2013) investigated the impacts of intellectual capital on other components and their effects on organizational learning capability. They reported that human capital, relational capital and learning

*Corresponding author.

E-mail addresses: kafashzadehalireza@gmail.com (A. Kafashzadeh)

(C) 2013 Growing Science Ltd. All rights reserved.

doi: 10.5267/j.msl.2012.12.027

\begin{abstract}
During the past few years, there have been growing interests on intellectual capital due to industrial changes on the market. Thus, identifying different ways to create, manage, and evaluate the impact of intellectual capital has remained an open area of research. One of the most important organizational capabilities, which could help organizations create and share knowledge is to effectively use knowledge to create competitive advantage. The primary objective of this study is to investigate the effects of intellectual capital on other components and their impacts on organizational learning capability using structural equation modeling. The statistical population includes 500 employees of an Iranian organization. The study uses a sample size including 273 people using Morgan statistical table. In our survey, human capital influences positively (0.330) on structural capital, human capital influences positively on relational capital (0.47) and relational capital influences positively on structural capital (0.455). In addition human capital influences positively on learning capabilities (0.06), structural capital impacts learning capabilities (0.355) and relational capital on learning capabilities (0.545).
\end{abstract}

(c) 2013 Growing Science Ltd. All rights reserved. 
capabilities had positive effect on organizational performance and relational capital positively impacted learning capability and human capital influenced positively on relational capital.

According to Moullin (2002), capital is an essential source, which impacts certain areas and allows the individuals to get certain advantages through participation. Veismoradi et al. (2012) investigated the relationship between social capital and the learning organizational in one of Iranian organizations. They stated that social capital could impact learning organizational. Ali et al. (2012) studied the relationship between knowledge management practices and the organizational performance of Pakistan's telecommunication. They reported that knowledge management practices impacted organizational performance, which stated that organizations that prefer knowledge management practices got beneficial outcomes than their competitors did.

Saeidipour et al. (2012) investigated the effect of "emotional intelligence" on "organizational learning" among employees in an Iranian organization. They implemented Wesinger Emotional Intelligence Questionnaire and organizational learning questionnaire to collect the necessary data. They explained that emotional intelligence impacted on organizational learning. Hsu and Fang (2009) studied intellectual capital and new product development performance by investigating on the mediating impact of organizational learning capability. Riahi-Belkaoui (2003) investigated intellectual capital and firm performance of some US multinational firms.

Sonnier et al. (2007) investigated the relationship between profitability and disclosure to investigate the impact of intellectual capital. Organizational learning was an important source of contributing to firms' intangible assets. Organizational learning was built when each member understands the difference between optimal and present results and tries to resolve problems. Therefore, conventional method and scientific management are not able to use staff's capabilities. Effective implementation of staff is essential and organizational leadership needs reaching the necessary skills.

Valaski et al. (2012) executed an investigation on how ontologies were being used in the organizational learning process. They determined 353 papers from 11 different databases and after applying the exclusion criteria, the set was limited to 11 works, which clearly fitted to the criteria described for review process. They classified them based on the structure and level of the ontologies.

Yu Yuan Hung et al. (2010) utilized a survey information from a Taiwan high-tech industry to introduce an integrative framework of dynamic capability. They stated that although organizational learning culture substantially influenced performance, its effect was mediated by dynamic capability. They also gave some supporting evidence for the hypothesis that process alignment effects performance either directly or indirectly through dynamic capabilities.

In this paper, we present an empirical study to re-examine the previously published work by Darvish et al. (2013) using structural equation modeling. The organization of this paper first presents details of the hypotheses in section 2 and section 3 presents details of our results. The paper ends with concluding remarks to summarize the contribution of the paper.

\section{The proposed study}

The main hypothesis of this survey is as follows,

Hypothesis 1: Three components of intellectual capital including human capital, structural capital and relational capital influence on each other.

The first hypothesis consists of three sub-hypothesis as follows,

1. Human capital influences positively on structural capital.

2. Human capital influences positively on relational capital. 
3. Relational capital influences positively on structural capital.

Hypothesis 2: Three components of intellectual capital including human capital, structural capital and relational capital influence learning capabilities. The second hypothesis consists of three sub-hypothesis as follows,

1. Human capital influences positively on learning capabilities.

2. Structural capital influences positively on learning capabilities.

3. Relational capital influences positively on learning capabilities.

The proposed study of this paper uses the following formula to calculate the minimum number of sample size,

$$
n=\frac{N \times z_{\alpha / 2}^{2} \times p \times q}{\varepsilon^{2} \times(N-1)+z_{\alpha / 2}^{2} \times p \times q},
$$

where $N$ is the population size, $p=1-q$ represents the yes/no categories, $z_{\alpha / 2}$ is CDF of normal distribution and finally $\varepsilon=0.04$ is the error term. Since we have $p=0.5, z_{\alpha / 2}=1.96$ and $N=500$, the number of sample size is calculated as $n=273$. The proposed study of this paper designed a questionnaire based on the existing literature (Bontis et al., 1999; Bontis et al., 2000; Bontis \& Serenko, 2009; Brooking, 1996). Cronbach alpha (Cronbach, 1951) is calculated as 0.898, which is well above the minimum acceptable level.

In terms of gender, $94.6 \%$ of the participants were male and only 5.4\% of them were female. Most of them were middle age people and $82.78 \%$ of them maintained bachelor degree of science, $13.55 \%$ of them had master or higher degrees and only 3.66\% of them maintained 2-year college degree.

Table 1 shows details of Pearson correlation test on five components of the survey.

\section{Table 1}

The results of Pearson correlation test

\begin{tabular}{lccccccc}
\hline Variable & $(1)$ & $(2)$ & $(3)$ & $(4)$ & AVE & \multicolumn{2}{c}{ Cronbach alpha } \\
\hline 1.Human capital (1) & 1 & Sig. $<0.01$ & Sig. $<0.01$ & Sig. $<0.01$ & 0.562 & - & 0.824 \\
2.Relational capital (2) & 0.47 & 1 & Sig. $<0.01$ & Sig. $<0.01$ & 0.565 & 0.221 & 0.697 \\
3.Structural capital (3) & 0.544 & 0.61 & 1 & Sig. $<0.01$ & 0.624 & 0.457 & 0.821 \\
4.Learning capabilities (2) & 0.51 & 0.79 & 0.721 & 1 & 0.565 & 0.718 & 0.805 \\
\hline
\end{tabular}

As we can observe from the results of Table 1, there are positive correlations between learning capabilities, human capital, relational capital from one side and organizational performance from the other side when the level of significance is one percent. In addition, there are some positive correlations between learning capabilities with human and relational capital when the level of significance is five percent. Finally, we observe a positive correlation between relational capability and human capital when the level of significance is five percent. Cronbach alpha are calculated within the desirable limit, which validates the results.

\section{The results}

In this section, we use regression analysis to study the effects of different variables on organizational performance. The first regression model is as follows, 


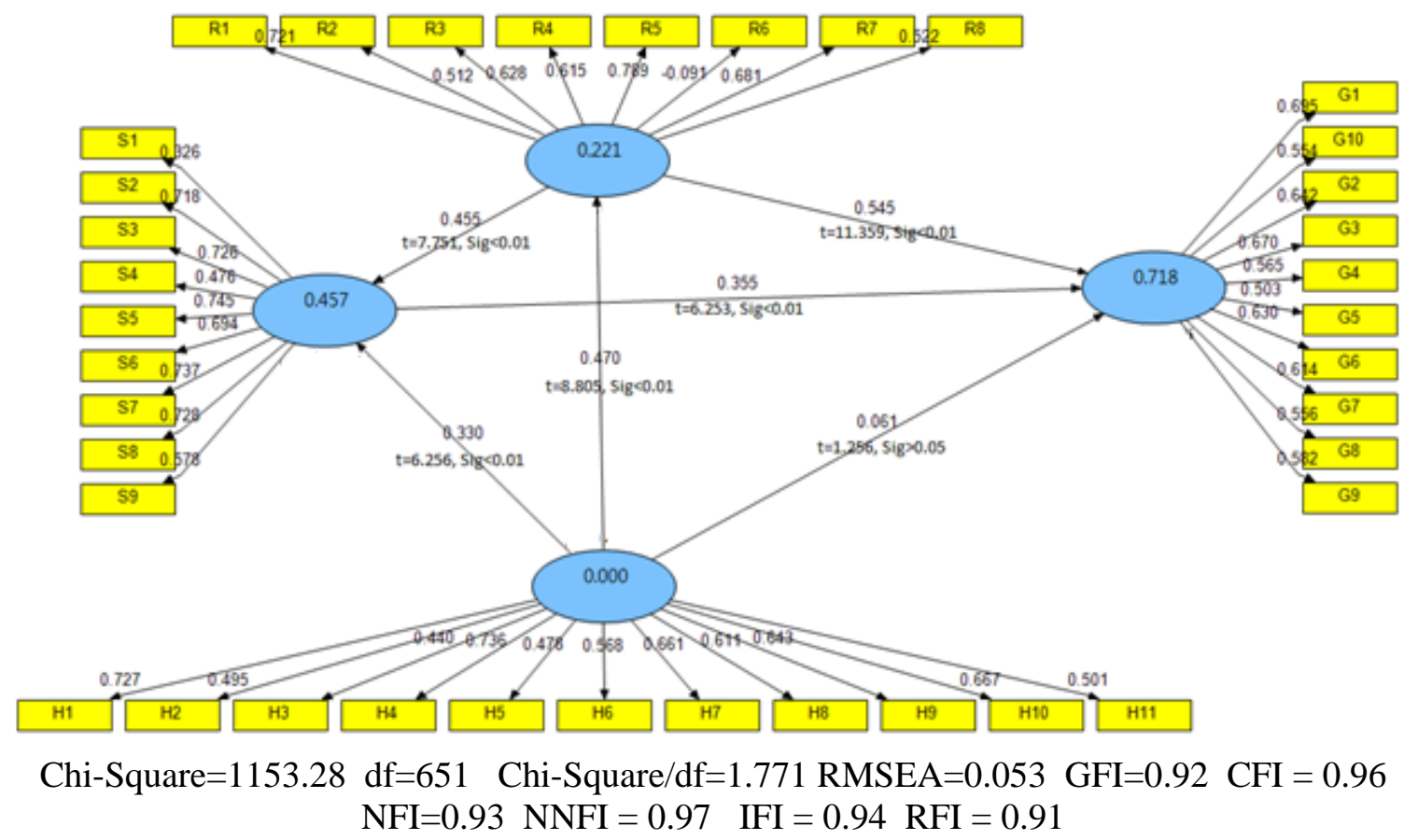

Fig. 1. The framework of the structural equation modeling and their effects and t-student values

In Fig. 1, the top ellipse is associated with relational capital (0.221), the left ellipse represents structural capital (0.457), the right ellipse is associated with learning capability and downside ellipse is related to human capital (0.000). Ellipse boxes represent hidden variables and rectangular boxes represent explicit variables. Statistical observations including Chi-Square/df, RMSEA, GFI, CFI and other components relatively confirm the results. There are two groups of variables in Fig. 1, which are endogenous or downstream and exogenous or upstream. The endogenous or downstream variables accept influences from other variables. However, exogenous or upstream do not accept any influence from other variables and, in fact, these variables impact other variables. Any number between ellipse and rectangular represent loading factor and other relationships are path coefficients and the bigger number represents the bigger impact.

Based on the results shown in Fig. 1, the first sub-hypothesis associated with the first hypothesis has been confirmed and we can conclude that human capital influences positively (0.330) on structural capital. The second sub-hypothesis studies whether human capital influences positively on relational capital and according to our survey there is a positive relationship (0.47) between these two components. The third sub-hypothesis investigates the relationship between relational capital on structural capital and according to the results of Fig. 1, relational capital influences positively on structural capital (0.455). Therefore, we can confirm the first main hypothesis.

The first sub-hypothesis of the second hypothesis is associated with relationship between human capital and learning capabilities and according to our survey there was a weak relationship between these two components (0.06) and we can conclude that human capital influences positively on learning capabilities. The second sub-hypothesis studies the relationship between structural capital and learning capabilities and the results of our survey indicates that there is a positive (0.355) from structural capital towards learning capabilities. Finally, the last sub-hypothesis investigates the relationship between relational capital and learning capabilities and the results of our survey indicates that there is a positive effect from relational capital on learning capabilities (0.545). Therefore, the second main hypothesis is also confirmed. 


\section{Conclusion}

In this paper, we have studied the impact of human, structural and relational capital on organizational learning using structural equation modeling. The study has been used for a real-world case study in Iran and the results have indicated that human capital, relational capital and learning capabilities have positive impact on organizational performance. In our survey, human capital influences positively (0.330) on structural capital, human capital influences positively on relational capital (0.47) and relational capital influences positively on structural capital (0.455). In addition human capital influences positively on learning capabilities (0.06), structural capital impacts learning capabilities (0.355) and relational capital on learning capabilities (0.545).

\section{Acknowledgment}

The authors would like to thank the help and insights provided by anonymous referees on earlier version of this paper.

\section{References}

Ali, A.M., Qadus, A., Waseem, A., \& Zaman, K. (2012). Linking knowledge management practices and the organizational performance of Pakistan's telecommunication. Management Science Letters, 2(8), 2929-2938.

Bontis, N., Dragonetty, N.C., Jacobsen, K., \& Roos, G. (1999).The Knowledge Toolbox: A review of the tools available to measure and manage intangible resources. European Management Journal, 17(14), 391-402.

Bontis, N., Keow, W.C.C., \& Richardson, S. (2000). Intellectual capital and business performance in Malaysian industries. Journal of Intellectual Capital, 1(1), 85-100.

Bontis, N., \& Serenko, A. (2009). A causal model of human capital antecedents and consequents in the financial services industry. Journal of Intellectual Capital, 10(1), 53-69.

Brooking, A. (1996). Intellectual Capital: Core Assets for the Third Millennium Enterprise. International Thompson Business Press, London.

Cronbach, L. J. (1951). Coefficient alpha and the internal structure of tests. Psychometrika, 16(3), 297-334.

Darvish, H., Ahmadi, A.A., Kafashzadeh, A.R., \& Farid, S. (2013). Investigating the effects of intellectual capital on organizational performance measurement through organizational learning capabilities. Management Science Letters, 3(1), 165-172.

Hsu Y., \& Fang W. (2009). Intellectual capital and new product development performance: The mediating role of organizational learning capability. Technological Forecasting and Social Change, 76(5), 664-677.

Moullin, M. (2002). Delivering Excellence in Health and Social Care. Buckingham, Open University Press.

Riahi-Belkaoui, A. (2003).Intellectual capital and firm performance of US multinational firms. Journal of Intellectual Capital, 4 (2), 215-226.

Saeidipour, B., Akbari, P., Marati Fashi, M.A. (2012). Study the effect of emotional intelligence on organizational learning staff, Case study: Jihad Agriculture Organization of Isfahan. Management Science Letters, 2(7), 2501-2510.

Sonnier, B. M., Carson, D. C., \& Carson, P. P. (2007). Accounting for Intellectual Capital: The Relationship between Profitability and Disclosure. Journal of Applied Management and Entrepreneurship, 12 (2), 3-14.

Stewart, T. A. (1997). Intellectual Capital: The New Wealth of Organizations. New York: Doubleday. 
Veismoradi, A., Akbari, P., \& Rostami, R. (2012). A study on the effect of social capital on learning organization: A case study of Jihad Agriculture Organization of Kermanshah, Iran. Management Science Letters, 2(8), 2909-2916.

Valaski, J., Malucelli, A., \& Reinehr, S. (2012). Ontologies application in organizational learning: A literature review Review Article. Expert Systems with Applications, 39(8), 7555-7561.

Yu Yuan Hung, R., Yang, B., Ya-Hui Lien, B., McLean, G.N., \& Kuo, Y.M. (2010). Dynamic capability: Impact of process alignment and organizational learning culture on performance. Journal of World Business, 45(3), 285-294. 